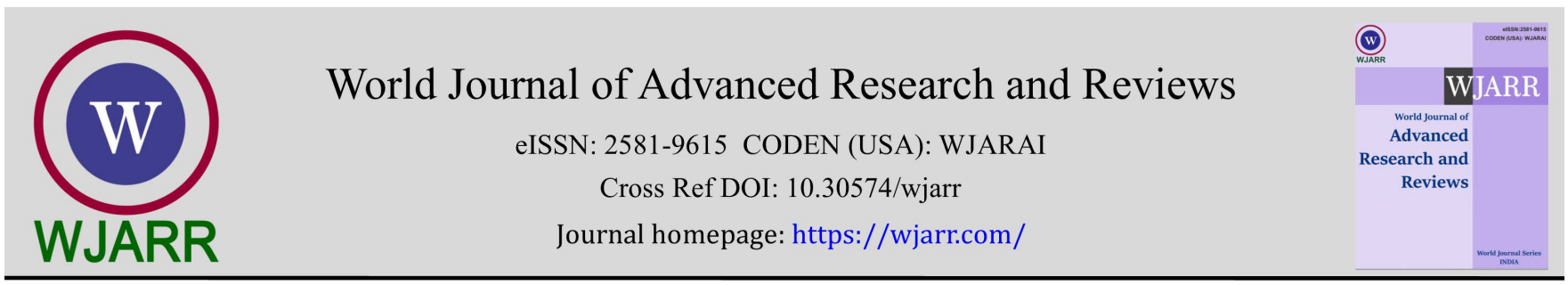

(RESEARCH ARTICLE)

Check for updates

\title{
Studies on excess molar volumes and viscosity deviations of binary mixtures of household kerosene and premium motor spirit at 303K
}

\author{
Anderson U. Ezeibe 1, Emmanuel C. Nleonu 1, ${ }^{*}$, Kelechi G. Ubaka ${ }^{1}$, Nadia Arrousse ${ }^{2}$ and Brandy O. Nleonu ${ }^{3}$ \\ ${ }^{1}$ Department of Chemistry/Biochemistry, Federal Polytechnic Nekede, Owerri-Imo state. \\ ${ }^{2}$ Laboratory of Engineering, Electrochemistry, Modeling and Environment (LIEME), Faculty of Sciences, University Sidi \\ Mohamed Ben Abdellah, Fez, Morocco. \\ ${ }^{3}$ Department of Mathematics and Statistics, Federal Polytechnic Nekede, Owerri-Imo State.
}

World Journal of Advanced Research and Reviews, 2021, 12(02), 616-620

Publication history: Received on 06 October 2021; revised on 25 November 2021; accepted on 27 November 2021

Article DOI: https://doi.org/10.30574/wjarr.2021.12.2.0588

\begin{abstract}
Density and viscosity of binary liquid mixtures of household kerosene (HHK) and premium motor spirit (PMS) were determined over the entire range of mole fraction at $303 \mathrm{~K}$. Excess molar volume $\left(\mathrm{V}^{\mathrm{E}}\right)$, molar volume $\left(\mathrm{V}_{\mathrm{m}}\right)$, Excess Viscosity $\left(\eta^{\mathrm{E}}\right)$, Viscosity deviations $(\Delta \eta)$ and excess Gibbs free energies of activation of viscous flow $\left(\Delta \mathrm{G}^{\mathrm{E}}\right)$ were calculated. The results obtained shows that excess free energy of activation were all positive over the entire mole fraction. The viscosity deviation shows both negative and positive values. The positive $\mathrm{V}^{\mathrm{E}}$ obtained in this study shows increase in volume in the binary mixture. This work will help in effective monitoring, detection of adulterated kerosene and subsequent enforcement of severe penalty on such adulteration.
\end{abstract}

Keywords: Household Kerosene; Premium Motor Spirit; Density; Excess Molar Volume; Excess Gibbs free energy

\section{Introduction}

The mixing of different solvents results in the formation of a solution that is different from individual solvents. The study of mixtures through their thermodynamic properties is important in understanding their mixing behavior [1]. Knowledge of thermodynamic properties of non-aqueous solutions is essential in many chemical and industrial applications.

Among the various thermodynamic properties, the excess molar volume $V^{E}$ has been of much interest for the practical purpose of determining composition of mixtures from the density measurement [2]. The studies of Excess properties such as deviation in viscosity, Excess molar volume and Excess Gibbs free energy of activation of viscous flow of binary mixtures are useful in understanding the nature of intermolecular interactions between two liquids $[3,4]$. Kerosene is a colourless combustible hydrocarbon used mainly for cooking and lighting. Where different products of comparable qualities have different prices or consumers have no efficient tools to distinguish similar products of different qualities, unscrupulous operators will always try to exploit the situation for illegal profits [5].

In Nigeria, the adulteration of kerosene is normally indulged by some unscrupulous kerosene dealers in their bid to make illegal profit from the sale of the product [6]. In the past, officials of National Union of Petroleum and Natural Gas Workers (NUPENG) have confirmed that some major dealers mix kerosene with other products such as PMS and Gasoline in various proportions to obtain the product of higher monetary value and in high demand to make abnormal profits [6].The poor in Nigeria depend on kerosene for their cooking energy needs and currently, kerosene is sold in

${ }^{*}$ Corresponding author: Nleonu EC

Department of Chemistry/Biochemistry, Federal Polytechnic Nekede, Owerri-Imo state

Copyright (C) 2021 Author(s) retain the copyright of this article. This article is published under the terms of the Creative Commons Attribution Liscense 4.0. 
major cities above $\$ 200$ per liter while premium motor spirit (PMS) is sold at $\$ 145$ per liter. The price differential has resulted in illegal adulteration of kerosene with PMS. A mixture of both liquids is miscible, making it difficult to detect the fraud. Kerosene adulteration had been implicated in all the various kerosene explosions in Nigeria [6], and as a result several lives have been lost and properties destroyed. Agencies of government saddled with the responsibility of monitoring and detection of such fraud as well as enforcement of standards of such products have been failing in their responsibility, hence the need to devise simple techniques for such determinations.

In this present study, density $(\rho)$ and viscosity $(\eta)$ of binary mixture of household kerosene (HHK) and premium motor spirit (PMS) are reported at $303 \mathrm{~K}$. Deviation in viscosity $(\Delta \eta)$, excess viscosity $\left(\eta^{\mathrm{E}}\right)$, molar volume $\left(V_{\mathrm{m}}\right)$, Excess molar volume $\left(\mathrm{V}^{\mathrm{E}}\right)$ and Excess Gibbs free energy of activation of viscous flow $\left(\Delta \mathrm{G}^{\mathrm{E}}\right)$ over entire mole fractions were calculated from the density $(\rho)$ and viscosity $(\eta)$ data. This study is expected to give information on the volume changes in this binary solution that explains intermolecular interactions in the mixture.

\section{Material and methods}

Household Kerosene and premium motor spirit were purchased from Empire Filling Station along Aba - Owerri road, Imo State. For the mixture preparation of HHK and PMS, nine sets of sample mixture were prepared in $\mathrm{X}_{1}, \mathrm{DPK}$ : $\mathrm{X}_{2}, \mathrm{PMS}$ ratio $90: 10,80: 20,70: 30,60: 40,50: 50,40: 60,30: 70,20: 80$, and 10:90.

Densities of pure liquids and various mixtures were measured at $303 \mathrm{~K}$ by using density bottle of $100 \mathrm{~cm}^{3}$ capacity. A single pan electronic precision analytical balance with a precision of $0.001 \mathrm{~g}$ was used for weighing purpose.

Viscosity measurements were carried out using digital NDJ - 85N viscometer with precision $\pm 0.01 \%$. The viscometer has a dynamic viscosity range of $0.01 \mathrm{~Pa}$.S to 2000Pa.S.

\section{Results and discussion}

To investigate the molecular interaction between Household kerosene (HHK) and premium motor spirit (PMS),excess molar volumes $\left(V^{\mathrm{E}}\right)$, deviation in viscosity $(\Delta \eta)$, excess viscosity $\left(\eta^{\mathrm{E}}\right)$, and excess Gibbs free energy of activation of viscous flow $\left(\Delta \mathrm{G}^{\mathrm{E}}\right)$ were calculated from experimental density and viscosity using the method described in our earlier work as stated in equations 1 - 4 respectively [7].

$V^{E}=\frac{x_{1} M_{1}+x_{2} M_{2}}{\rho_{m}}-\left[\frac{x_{1} M_{1}}{\rho_{1}}+\frac{x_{2} M_{2}}{\rho_{2}}\right]$

$\Delta \eta=\eta_{m}-\left(x_{1} \eta_{1}+x_{2} \eta_{2}\right)$

$\eta^{\mathrm{E}}=\eta_{\text {mix }}-\left(x_{1} \eta_{1}-x_{2} \eta_{2}\right)$

Where $\mathrm{x}_{1}$ (HHK) and $\mathrm{x}_{2}$ (PMS) are the mole fractions calculated from mass fractions. $M_{1}(170.33 \mathrm{~g} / \mathrm{mol})$ and $M_{2}(150 \mathrm{~g} / \mathrm{mol})$ are molar masses, $\rho_{1}$ and $\rho_{2}$ are densities, $\eta_{1}$ and $\eta_{2}$ are the viscosities of pure components 1 and 2 respectively. $P_{m}$ and $\eta_{m}$ are the density and viscosity of the mixture.

The excess Gibbs free energy of activation of viscous flow was obtained from equation 4.

$\Delta G^{\# E}=R T\left[\ln \eta_{m} V_{m}-\left(x_{1} \ln \eta_{1} V_{1}+x_{2} \ln \eta_{2} V_{2}\right)\right.$

Where $\mathrm{R}$ is the universal constant of gases, $\mathrm{T}$ is the absolute temperature, $V_{1}$ and $V_{2}$ are the molar volumes of HHK and PMS, $\mathrm{x}_{1}$ and $\mathrm{x}_{2}$ represents the mole fraction of HHK and PMS. $V_{m}$ is obtained from equation 5 below. $\eta_{1}, \eta_{2}$ and $\eta_{m}$ are the viscosity of HHK, PMS and mixture respectively.

$V m=\frac{x_{1} M_{1}+x_{2} M_{2}}{\rho_{m}}$

Experimental density $(\rho)$, viscosity, deviation in viscosity $(\Delta \eta)$, excess viscosity $\left(\eta^{\mathrm{E}}\right)$, excess molar volume $\left(\mathrm{V}^{\mathrm{E}}\right)$ and excess Gibbs free energy of activation of viscous flow $\left(\Delta \mathrm{G}^{\mathrm{E}}\right)$ for HHK and PMS as a function of mole fraction and presented in table 1. 
The graphical representation of $\Delta \eta, \eta^{\mathrm{E}}, \mathrm{V}^{\mathrm{E}}$, and $\Delta \mathrm{G}^{\mathrm{E}}$ for binary solution of HHK and PMS at 303k over the entire mole fraction are represented in figure 1-4 respectively.

Table 1 Experimental densities $(\rho)$, viscosity deviation $(\Delta \eta)$, excess viscosity $\left(\eta^{E}\right)$, molar volume $\left(V_{m}\right)$, Excess Molar Volume $\left(V^{E}\right)$ and excess Gibb's free energy $\left(\Delta G^{E}\right)$ for the binary mixture of household kerosene and premium motor spirit at $303 \mathrm{~K}$.

\begin{tabular}{|c|c|c|c|c|c|c|}
\hline$X_{1}$ & $\begin{array}{c}\rho \\
\left(\mathrm{g} / \mathrm{cm}^{3}\right)\end{array}$ & $\Delta \eta(\mathrm{Pa} . \mathrm{s})$ & $\eta^{\mathrm{E}}(\mathrm{Pa} . \mathrm{S})$ & $\begin{array}{c}V_{\mathrm{m}} \\
\left(\mathrm{cm}^{3} / \mathrm{mol}\right)\end{array}$ & $\begin{array}{c}\mathrm{V}^{\mathrm{E}} \\
\left(\mathrm{cm}^{3} / \mathrm{mol}\right)\end{array}$ & $\begin{array}{r}\Delta G^{E} \\
(J / m o l)\end{array}$ \\
\hline 1.00 & 0.7623 & 0 & 0 & 0.00 & $\begin{array}{llll}0 & . & 0 & 0\end{array}$ & 6221.65 \\
\hline 0.9107 & 0.7463 & -0.0023 & 0.0057 & 225.39 & 3.66 & 689.82 \\
\hline 0.8193 & 0.7406 & 0.0015 & 0.0177 & 224.67 & 4.23 & 1313.13 \\
\hline 0.7256 & 0.7378 & -0.0028 & 0.0218 & 222.97 & 3.87 & 1389.06 \\
\hline 0.6296 & 0.7351 & -0.0001 & 0.0333 & 221.19 & 3.45 & 1702.20 \\
\hline 0.5313 & 0.7329 & -0.0033 & 0.0389 & 219.15 & 2.83 & 1611.64 \\
\hline 0.4304 & 0.7269 & 0.0026 & 0.0538 & 218.19 & 3.30 & 1899.31 \\
\hline 0.3269 & 0.7196 & 0.0024 & 0.0630 & 217.54 & 4.11 & 1771.84 \\
\hline 0.2208 & 0.7165 & 0.0012 & 0.0714 & 215.51 & 3.60 & 1444.86 \\
\hline 0.1118 & 0.7141 & 0.0019 & 0.0781 & 213.20 & 2.83 & 813.78 \\
\hline 0.00 & 0.7185 & 0.00 & $\begin{array}{llll}0 & 0 & 0 & 0\end{array}$ & $\begin{array}{llll}0 & . & 0 & 0\end{array}$ & $\begin{array}{llll}0 & . & 0 & 0\end{array}$ & 5643.21 \\
\hline
\end{tabular}

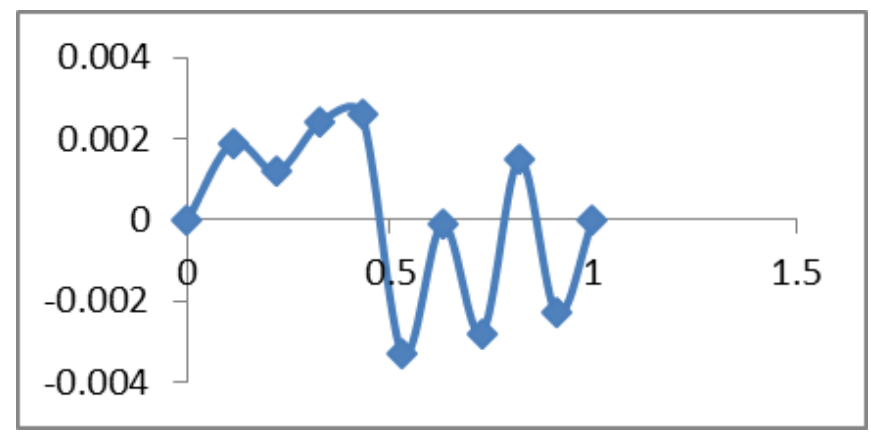

Figure 1 Plot of viscosity deviation against Mole Fraction for HHK and PMS at 303K

The plot of viscosity deviation against mole fraction at 303k for HHK and PMS are presented in figure 1 . Viscosity deviation were found to be negative at HHK and PMS ratio of 90:10, 70:30, 60:40, 50:50, 10:90\% respectively while positive deviation were observed in their ratio proportions. The negative values of viscosity deviation $(\Delta \eta)$ suggest the existence of weak intermolecular interaction upon mixing HHK and PMS. While the positive values of deviation observed in some proportions relate to strong intermolecular interaction between the mixtures.

The viscosity deviation observed in the mixtures is not influenced by the strength of the specific forces but suggest that combinations of an interactive and non-interactive force are responsible for positive and negative interactions observed $[1,3]$.

The plot of excess viscosity against mole fraction of 303k for binary mixture of HHK and PMS are represented in figure 2. The excess viscosity of the mixture shows that these values decrease as HHK composition decreases in the mixture. Excess viscosity was positive over the specific mole composition of the mixture at the studied temperature, indicating increase in molecular size of the mixture. Various molecules dissolve in each other when mixed, if they have approximately the same type of polarity [8], which is the case in this situation. 


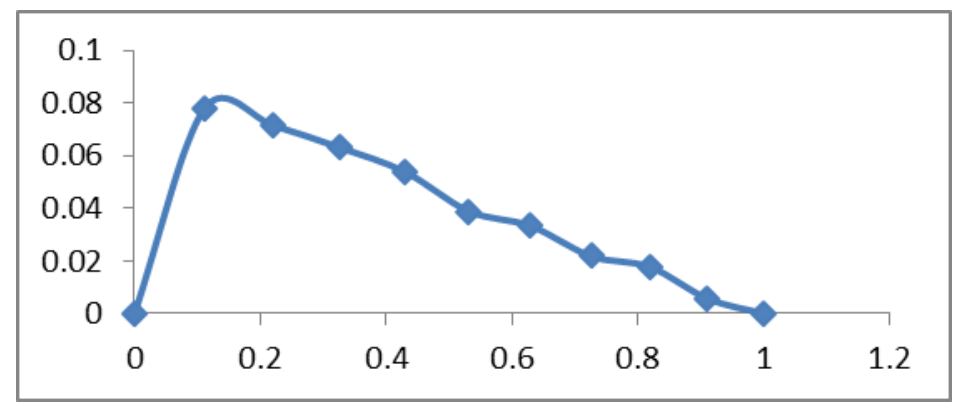

Figure 2 Plot of Excess viscosity against Mole Fraction for HHK and PMS at 303K

Ideal binary liquid mixture formation is accompanied with no volume change, but due to molecular interactions between components of binary liquid mixture, they occur in real liquid mixture either with increase or decrease in volume ${ }^{[9]}$. This volume change $\left(\mathrm{V}^{\mathrm{E}}\right)$ for the binary mixture can be taken as a criterion for measurement of molecular interaction [9]. The plot of excess molar volume $\left(\mathrm{VE}^{\mathrm{E}}\right)$ against mole fraction of the mixture is presented in figure 3 . Excess parameters associated with a liquid mixture are a quantitative measure of deviation in the behaviour of the liquid mixture from ideality [1].

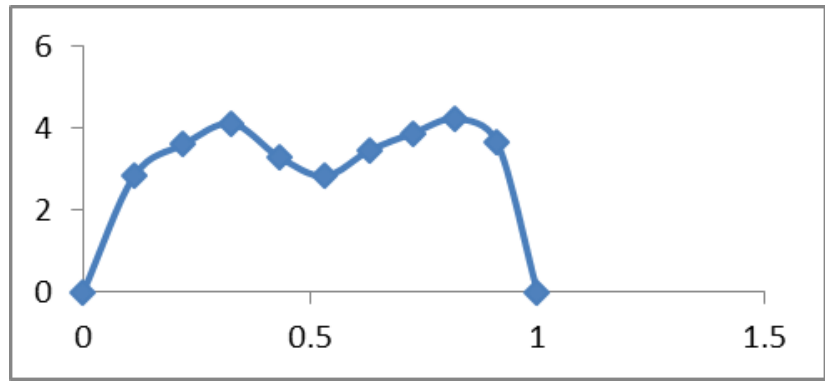

Figure 3 Plots of Excess molar volume against Mole Fraction for HHK and PMS at 303K

The values of $\mathrm{V}^{\mathrm{E}}$ for the mixture of $\mathrm{HHK}$ and PMS were found to be positive over the entire mole composition. The positive excess molar volume can be attributed to dominance of dispersion forces between the solvents [10] or physical contribution of individual solvents, which are nonspecific interactions between the real species present in the mixture [11].

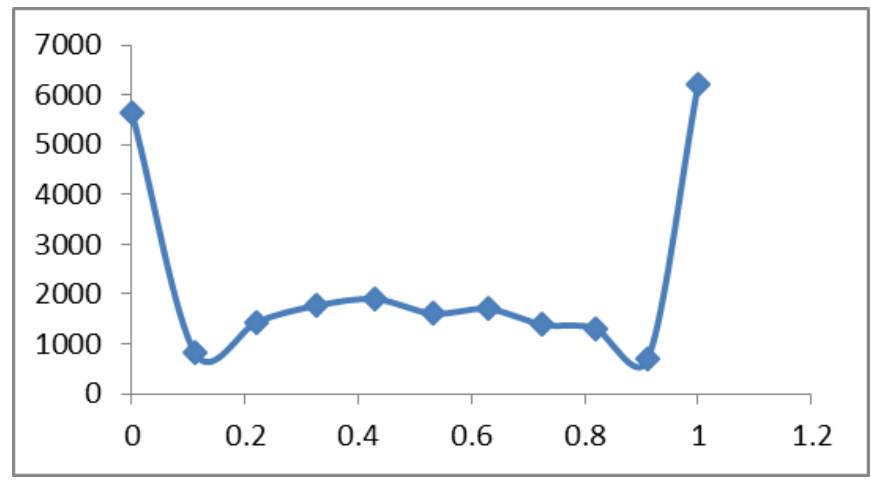

Figure 4 Plots of Excess Gibbs free energy against Mole Fraction for HHK and PMS at 303K

The plot of $\Delta \mathrm{G}^{\mathrm{E}}$ against mole fraction at 303K for binary mixture of household kerosene and premium motor spirit is presented in figure 4 . The $\Delta \mathrm{G}^{\mathrm{E}}$ was found to be positive for entire mole fractions. The positive values of excess Gibbs free energy of activation of viscous flow indicate the presence of specific and strong interactions in the systems studied [1,3]. The excess Gibbs free energy of activation of viscous flow attains a maximum at $40 \%$ of household kerosene. 


\section{Conclusion}

The density, deviation in viscosity, excess viscosity, molar volume, excess molar volume and excess Gibbs free energy of activation of viscous flow for the binary mixture of HHK and PMS at 303K has been studied and reported. There is an intermolecular interaction among the components of the binary mixtures caused by Vander Waals forces between the non-polar molecules. Periodic monitoring and enforcing of severe penalty is recommended to discourage kerosene adulteration by unscrupulous petroleum marketers.

\section{Compliance with ethical standards}

Ethics approval was not required for this research.

\section{Acknowledgments}

The authors appreciate facilities made available by Department of Chemistry/Biochemistry, Federal Polytechnic Nekede, Owerri-Imo state for carrying out this work.

\section{Disclosure of conflict of interest}

The authors hereby declare there is no conflict of interest.

\section{References}

[1] Dikio ED, Nelana SM, Isabiriye DA, Ebenso EE. Density, Dynamic Viscosity and Derived properties of Binary Mixtures of Methanol, Ethanol, n-Propanol and n-Butanol with Pyridine at $\mathrm{T}=(293.15,303.15,313.15$ and 323.15K). Int. J. Electrochem. Sci. 2012; 7: 11101 - 11122.

[2] Shalmashi A, Amani F.Densities and Excess Molar Volumes for Bonar Solution of Water + Ethanol, + Methanol and + Propanol from (283.15 to 313.15K). Latin American Applied Research. 2014; 44: 163-166.

[3] Satish BM, Machale GR, Gayakwad SV, Naikwade DS. Density, Viscosity and Excess Gibbs Free Energy of Activation of Binary Systems of Formaldehyde with Methanol, Ethanol, n-Propanol and N-Butanol at temperatures 298.15, 308.15 and 318.15K. International Journal of Engineering Trends and Technology. 2016; 41(5): 249-255.

[4] Wahab MA, Azhar A, Mottaleb MA. Volumetric Behaviour of Binary Liquid Mixtures at a Temperature of 303.15K. Bull. Korean Chem. Soc.2002;23: 953.

[5] Obodeh O, Akhere NC. Experimental Study on the Effects of Kerosene Doped Gasoline on Gasoline-Powered Engine Performance Characteristics. Journal of petroleum and Gas Engineering. 2010; 1(2): 37 - 40.

[6] Yekini OL. Kerosene Adulteration in Nigeria: Causes and Effects. American Journal of Social and Management Sciences. 2011; 2(4): $371-376$.

[7] Nleonu EC, Ezeibe AU, Onwusonye JC, Okeke PI, Ibe GC. Volumetric Behaviour of Binary Mixtures of Ethanol and Methanol at 303 and 308K. World Journal of Pharmaceutical Research. 2020;9(7): 207-214.

[8] Dikko AB, Eyube ES, Eke E. Studies on Density, Viscosity, Partial Molar Volume, Excess Molar Volume and Excess Viscosity of Panadol in Methanol + Water System at 309.15K. IOSR Journal of Applied Chemistry. 2015; 7(3): 6366.

[9] Patil PP, Patil SR, Borse AU, Hundiwale DG. Density, Excess Molar Volume and Apparent Molar Volume of Binary Liquid Mixtures. Rasayan J. Chem. 2011; 4(3): 599-604.

[10] Dakua KV, Sinha B, Roy NM. Studies on Excess Molar Volumes and Viscosity Deviations of Binary Mixtures of Butylamine and N, N-dimethylformamide with some Alkyl Acetates at 298.15K. Indian Journal of Chemistry. 2006; 45A: 1381-1389.

[11] Vural SU, Muradoglu V, Vural S. Excess Molar Volumes and Refractive Index of Binary Mixtures of Glycerol + Methanol and Glycerol + Water at 298.15 and 303.15K. Bull. Chem. Soc. Ethiop. 2011; 25(1): 111-118. 